\title{
Cardiovascular Examination
}

National Cancer Institute

\section{Source}

National Cancer Institute. Cardiovascular Examination. NCI Thesaurus. Code C122008.

Tests and assessments pertaining to the cardiovascular system. 